ECCOMAS

Proceedia
COMPDYN 2021

$8^{\text {th }}$ ECCOMAS Thematic Conference on Computational Methods in Structural Dynamics and Earthquake Engineering M. Papadrakakis, M. Fragiadakis (eds.)

\title{
COMPREHENSIVE NONLINEAR ANALYSIS OF FAILURES OF A FIRE-SPRINKLER SYSTEM BASED ON FINITE ELEMENT MODELLING AND AMBIENT VIBRATION TESTS
}

\author{
Shakhzod M. Takhirov ${ }^{1}$ and Amir S. Gilani ${ }^{2}$ \\ ${ }^{1}$ Department of Civil and Environmental Engineering, University of California, Berkeley \\ 337 Davis Hall, Berkeley, CA 94720, USA \\ e-mail: takhirov@berkeley.edu \\ ${ }^{2}$ Miyamoto International \\ 1450 Halyard Dr., West Sacramento, CA 95691, USA \\ e-mail: agilani@miyamotointernational.com
}

\begin{abstract}
In the aftermath of the 2014 South Napa Earthquake, several failures of fire-sprinkler systems were observed. The failures were related to excessive displacements of these systems leading to an uncontrolled interaction with the surrounding nonstructural components, e.g., suspended ceiling systems, light fixtures, and ventilation ducts. The large displacements of the firesprinkler system can be related to the support elements with under-designed flexibility and/or failures of the support elements in which demand exceeded capacity. In addition to the excessive interaction with the surrounding nonstructural components, the large displacements can result in failures of the joints that are designed to accommodate only a limited rotation. To investigate the seismic performance of a typical fire-sprinkler system, a building in Napa, California (USA) was selected. A fire-sprinkler system in this building was damaged by the 2014 South Napa Earthquake and the damages were captured in 3D with high accuracy by a laser scanner. A finite element model of this building was generated and studied earlier but was limited to elastic models of both the building and the fire-sprinkler system. Artificially large amplifications of the seismic excitation over the elevation of the building were observed. The building's model was evaluated based on the ambient vibration tests. Amplification of the seismic excitation over the elevation was estimated from an instrumented building with a similar design and resonant frequencies. The amplified seismic impact was imposed on the firesprinkler system, which was modelled as a system with nonlinear behavior.
\end{abstract}

Keywords: Fire-sprinkler System, Seismic Performance, Nonstructural Components, Ambient Vibration Study, Nonlinear Modelling. 


\section{INTRODUCTION}

A fire-sprinkler system represents a complex piping system suspended from the ceiling that spreads out in space and consists of many joints. To investigate the seismic performance of a typical fire-sprinkler system, a building in Napa, California (USA) was selected. The firesprinkler system in this building was damaged by the 2014 South Napa Earthquake and the damages were captured in 3D with high accuracy by a laser scanner. A finite element model of this building was generated and studied earlier [1] but it was limited to elastic models of both the building and the fire-sprinkler system. In this study, artificially large amplifications of the seismic excitation over the elevation of the building were observed. To address this shortcoming, a new model of the building and the fire-sprinkler system was generated. The building's model was calibrated based on the ambient vibration tests. Amplification of the seismic excitation over the elevation was estimated from an instrumented building with a similar design and resonant frequencies.

\section{AFTERMATH ANALYSIS BY LASER SCANNING}

Immediately after the 2014 South Napa Earthquake, the parking structure with a failed firesprinkler system was laser scanned by means of a C10 ScanStation from Leica Geosystems [2]. A global view of the building taken from Google Earth is shown in Figure 1a. The overall view of the point cloud collected during this scanning project is presented in Figure 1b. The point cloud presented in Figure $1 \mathrm{~b}$ is a registration of point clouds collected from more than 14 stations throughout the structure. The point cloud registration was conducted in Cyclone from Leica Geosystems [3].

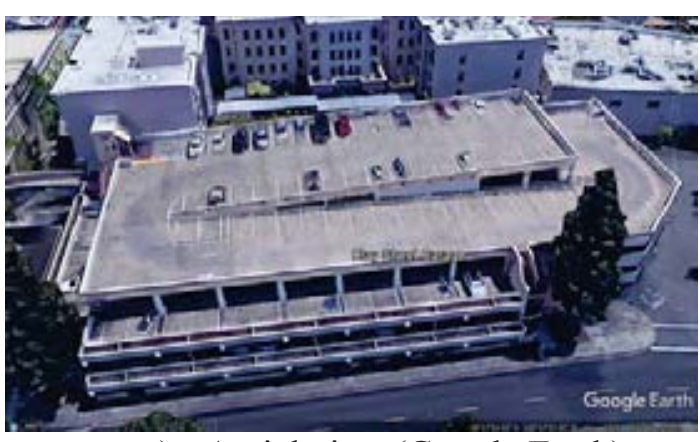

a) Aerial view (Google Earth)

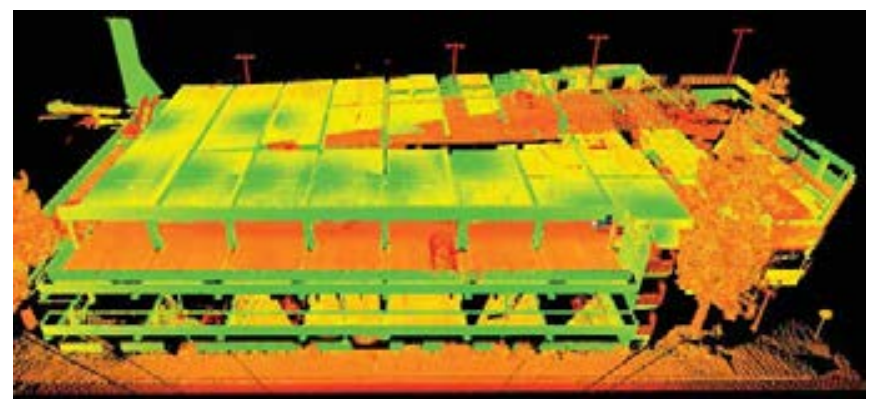

b) Point cloud

Figure 1: Overall view of the parking structure.

As was discussed in the earlier paper [1], most failures of the fire-sprinkler system were observed on the $3^{\text {rd }}$ floor of the structure, the structure's highest elevation, where the suspended fire-sprinkler system was located. In other words, this was the highest floor with a ceiling from which the system can be suspended. Therefore, this elevation was studied in more detail and 13 stations of the laser scanning project were conducted on this floor. As a result, all failures of the fire-sprinkler system were documented within a few millimeters of accuracy. In addition, the failures were captured from many points by the still imaging camera built into the scanner. A detailed discussion of the failures was provided in [1].

\section{RESULTS OF AMBIENT VIBRATION STUDY}

A solid element model of the parking structure was generated earlier. It was based on the geometry captured by the laser scanner and a few assumptions about the materials used in the structure's construction. To access the actual performance characteristics of the structure, an 
ambient vibration study was conducted. It was conducted on the top floor of the parking structure from which the fire-sprinkler system was suspended as presented in Figure 2a.

A portable data acquisition system (PI-6008U from Pacific Instruments [4]) was used in this study. The system has a flexibility in its power supply and as one of the available options it can be powered by a car battery. This power supply option was used in this study. The acceleration of the ambient vibrations was recorded.

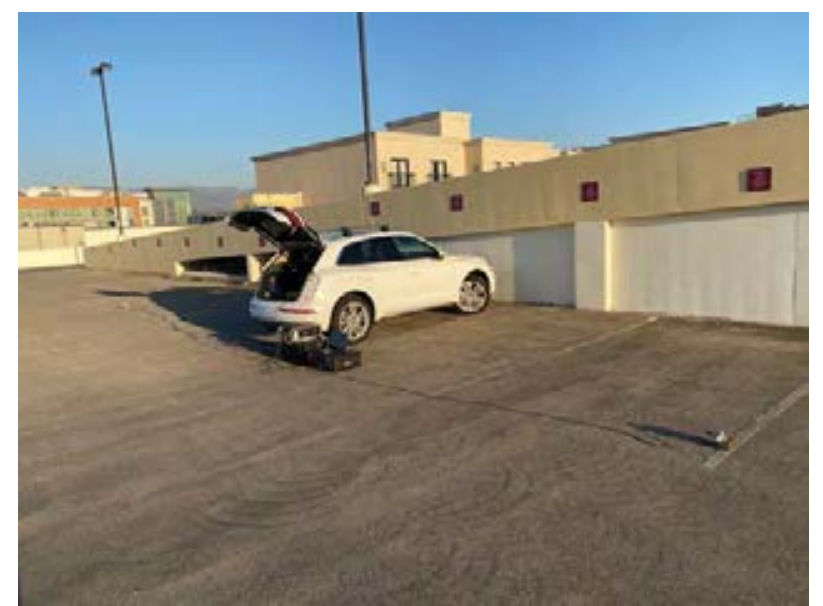

a) Global view of setup

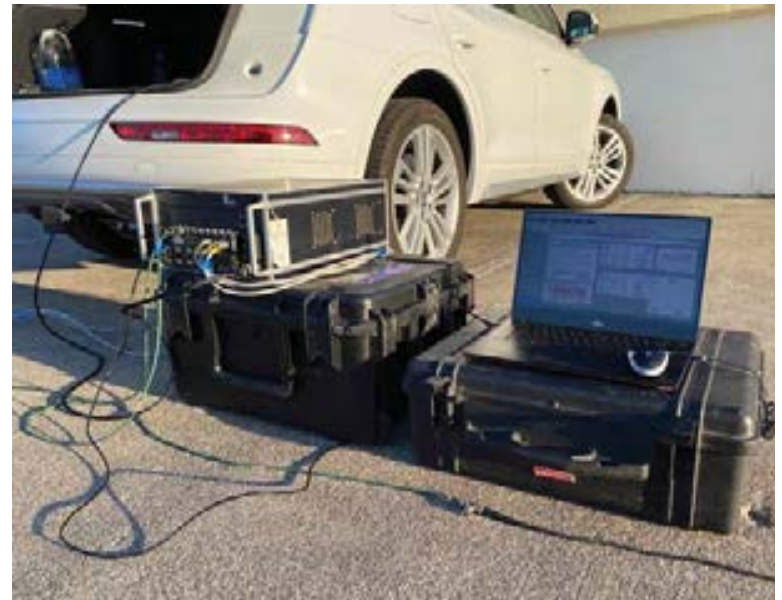

b) Data acquisition system and recording laptop

Figure 2: Setup of ambient vibration study.

Three different models of accelerometers were used. Two of them were of a piezoelectric type and the third one was a MEMS accelerometer. The results for one of the piezoelectric accelerometers discussed herein. The MEMS accelerometer was triaxial, therefore only the orientation of the piezoelectric accelerometers was changed to measure the structure's response in all three principal directions. The orientations of the piezoelectric accelerometer in $\mathrm{Z}$ and $\mathrm{X}$ are shown in Figure 3. The orientation of the accelerometer to measure the response in $\mathrm{Y}$ direction is presented in Figure 4a. The latter shows an example of another piezoelectric accelerometer. For comparative analysis of the MEMS and the piezoelectric accelerometer, both were installed on the same block as presented in Figure $4 \mathrm{~b}$.

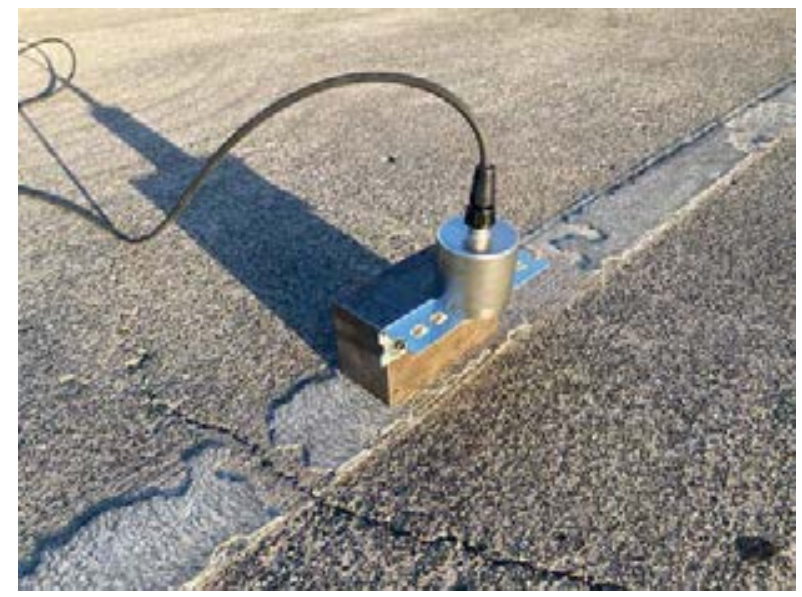

a) Up or vertical orientation (Z)

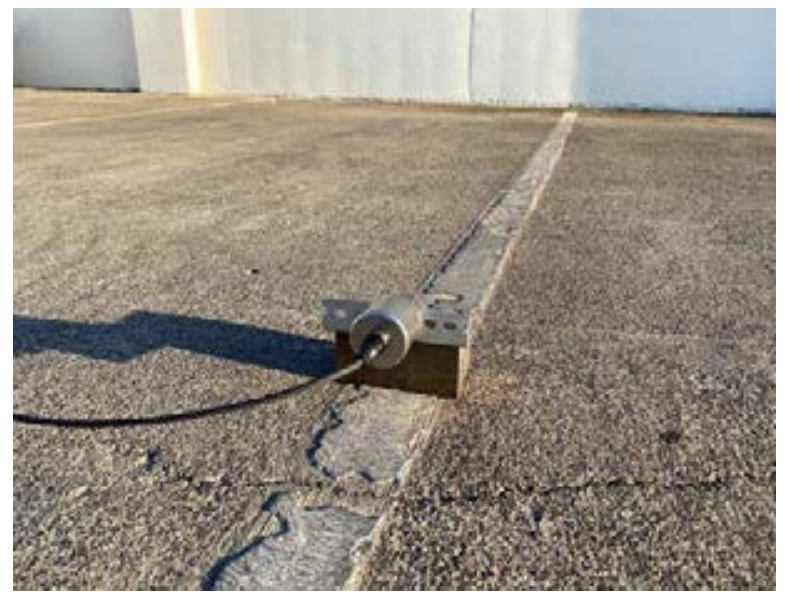

b) Transversal orientation $(\mathrm{X})$

Figure 3: Orientations of accelerometer to measure response in $\mathrm{Z}$ and $\mathrm{X}$. 


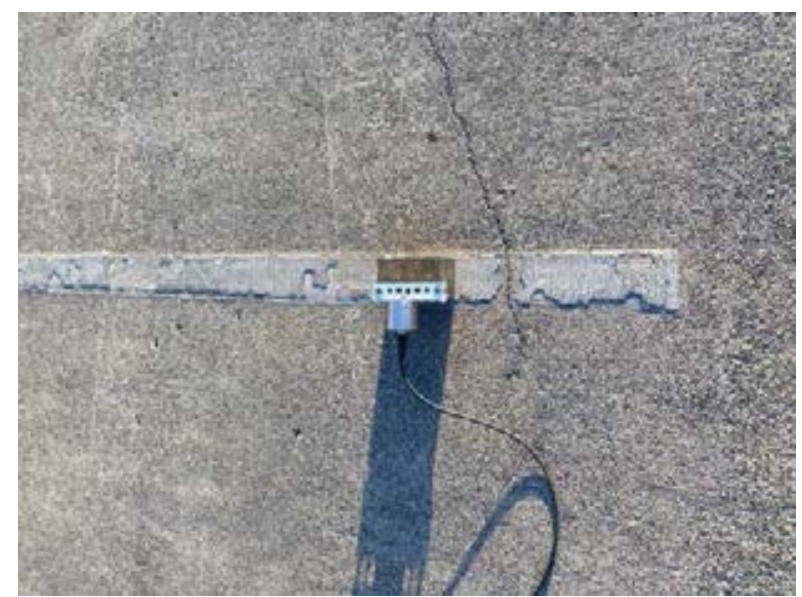

a) Longitudinal orientation (Y)

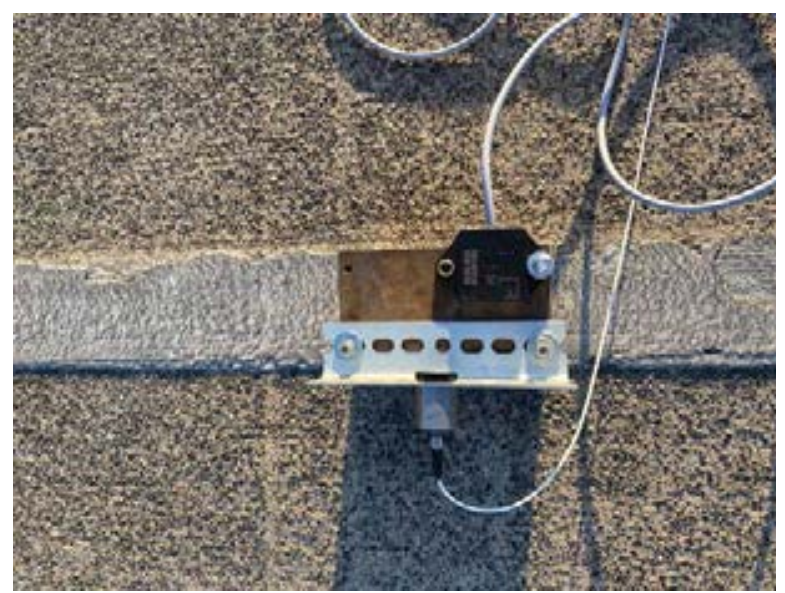

b) MEMS and piezoelectric accelerometer on the same block

Figure 4: Orientation of accelerometer in $\mathrm{Y}$ and two accelerometers sharing at the same location for a comparative study.

Typical results of the ambient vibration study are presented in Figure 5. Both plots show Fast Fourier Transforms of the acceleration records. The plot on the left is obtained for the orientation in the transversal axis of the structure and the plot on the right corresponds to the records obtained for the longitudinal orientation of the accelerometer. Based on these plots, the lowest resonant frequencies of the structure are $4.8 \mathrm{~Hz}$ and $6.9 \mathrm{~Hz}$ in the transversal and longitudinal directions, respectively.

It is worth noting that both resonant frequencies of the structure are located within the frequency range of the AC156's spectral plateau [5].

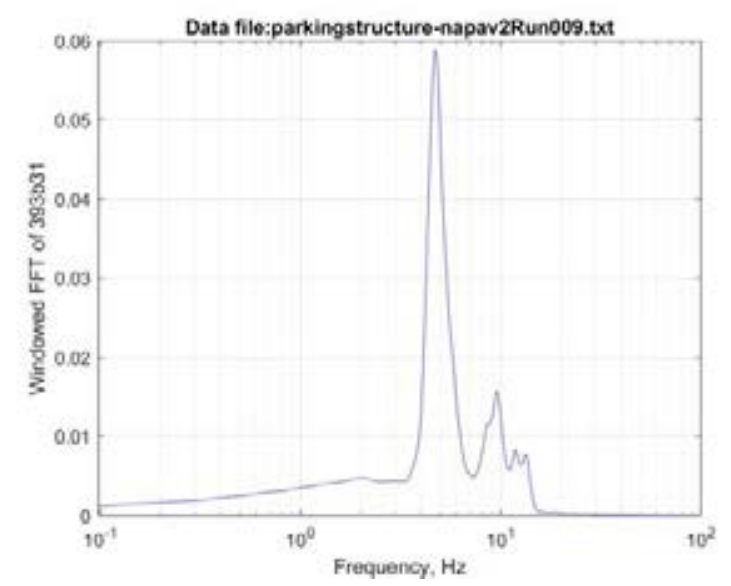

a) $\mathrm{X}$ or transversal axis

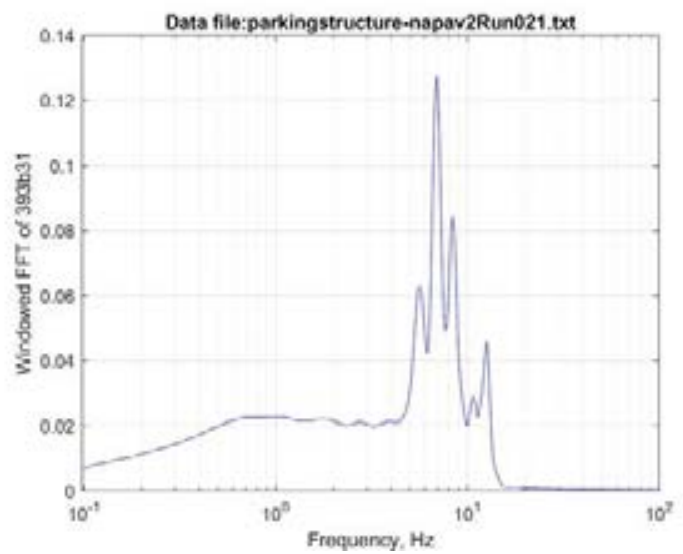

b) Y or longitudinal axis

Figure 5: Results of ambient vibration study.

\section{TIME HISTORY BASED ON AC156 SPECTRA}

A selection of a time history for the finite element analysis was based on requirements of AC156. The hazard level at the site was taken from the USGS's maps [6]. The $S_{S}$ values for California are presented in Figure 6a. In this figure the legend shows the correlation between the color and range of $S_{S}$ expressed in percent of g. Figure $6 \mathrm{~b}$ shows the close-up view of 
these maps with the city of Napa shown in the magenta box. A tri-axial time history satisfying the requirements of AC156 was developed earlier [7] and had been utilized for the nonstructural testing at the Pacific Earthquake Engineering Center (PEER) - UC Berkeley for quite some time. It was scaled accordingly, assuming a maximum value of $S_{S}$ for Napa.

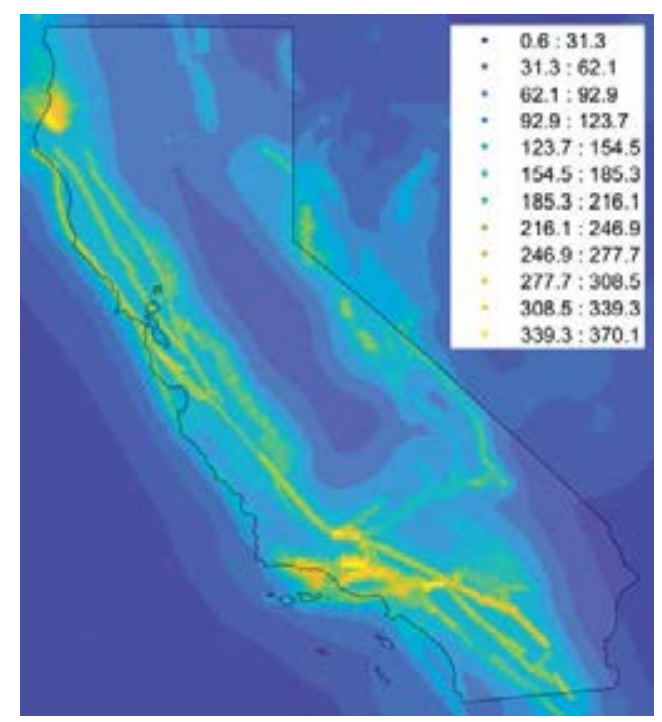

a) $S_{S}$ hazard map for California

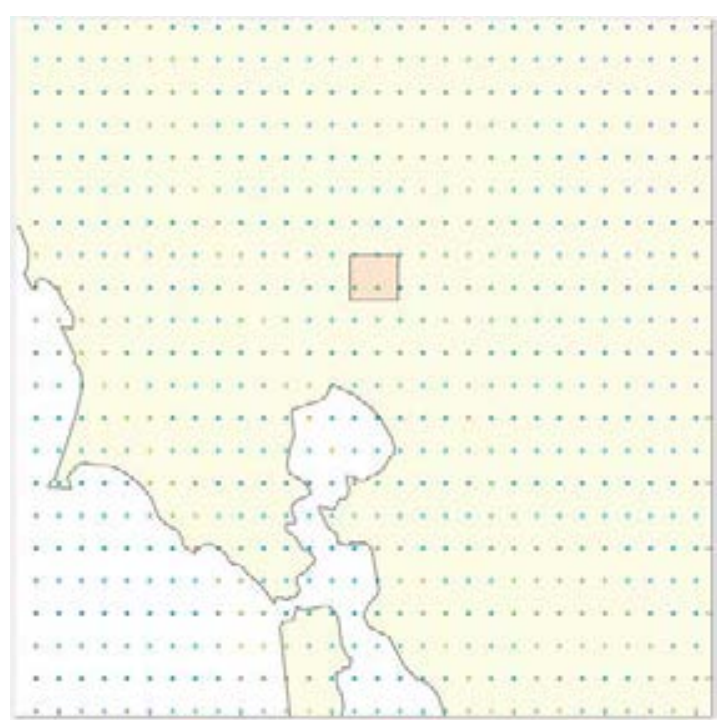

b) $S_{S}$ hazard map in vicinity of Napa, CA

Figure 6: Hazard maps

\section{FINITE ELEMENT MODEL}

All modelling was conducted in SAP2000 [8]. The finite element model of the piping system is presented in Figure 7. It was generated based on the laser scans. It consists of the main supply constructed of a $114-\mathrm{mm}$ pipe that branches out to a $50-\mathrm{mm}$ pipe with sprinkler heads at the very end. The 114-mm pipeline consists of 3 major sections. Section 1 of the main supply runs along the length of the structure and is parallel to the horizontal ceiling or the third floor. Section 2 is shorter and runs across the width of the structure. Section 3 also runs along the structure's length, but it is inclined to accommodate the sloped ceiling of the ramped section of the floor as opposed to Section 1.

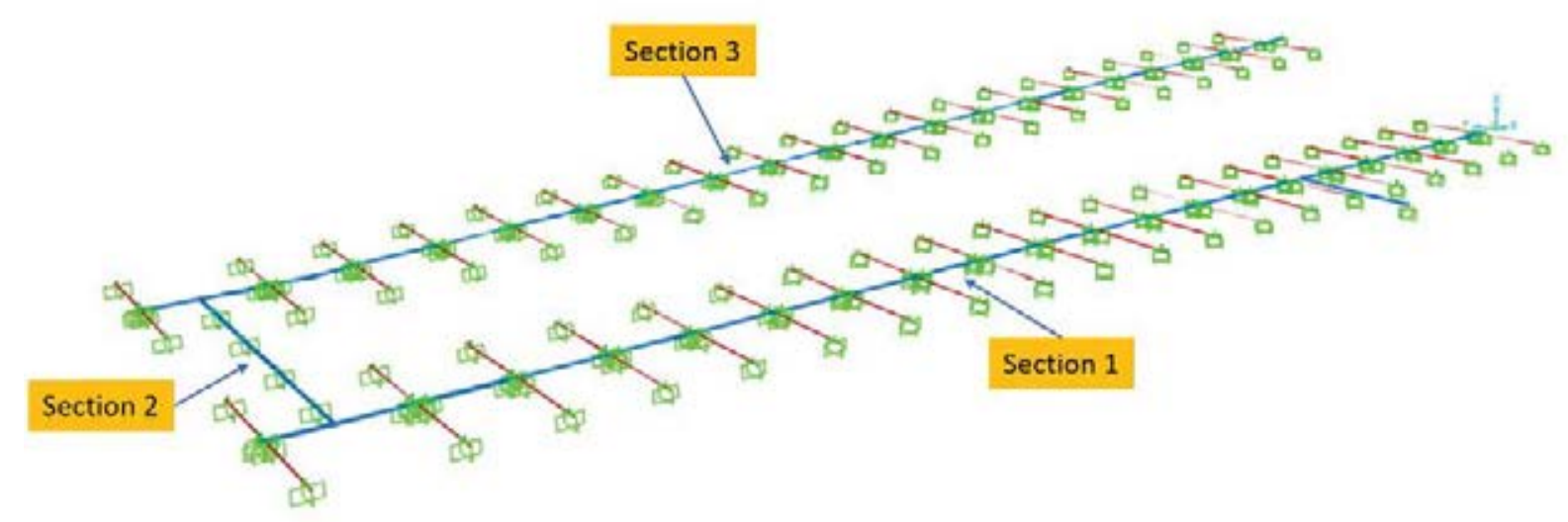

Figure 7: Finite element model of fire-sprinkler system.

All pipes were modelled as frames in SAP2000 terminology. The intersection points between the beams and the 114-mm pipelines were modelled as frictionless rollers allowing the 
pipe to move along its longitudinal axis and restraining the pipe in both the vertical and transverse directions. The effective mass of the pipelines was increased to account for the weight of the water inside the pipes.

Typical installations of rods used for suspending the piping system from the ceiling are shown in Figure 8. The supporting rods were modelled as rods with rigid connections to the pipes and the ceiling. Since the actual installation used the threaded rods, the effective diameter of the rods was reduced accordingly, and they were also modelled as elastic frames in the first stage of analysis.

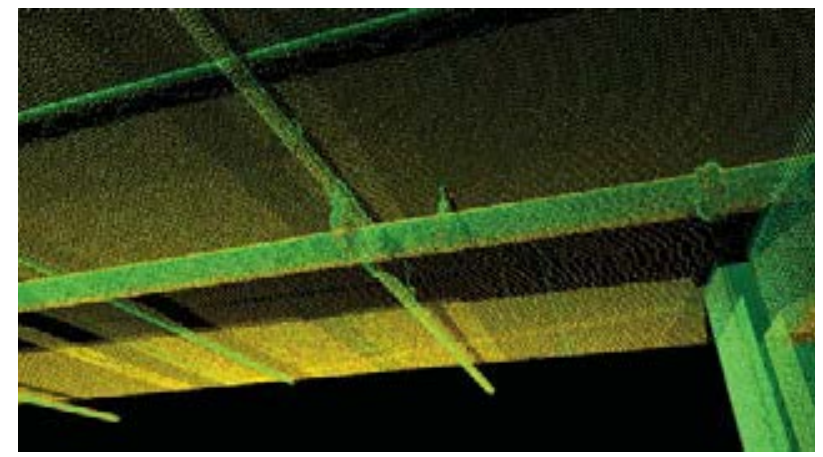

a) Large diameter pipe

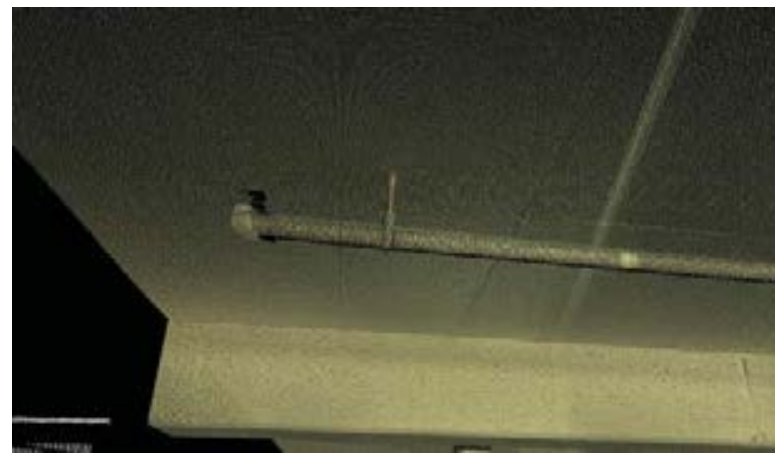

b) Small diameter pipe

Figure 8: Typical installation of supporting rods.

Based on the results of the time history analysis of the elastic FE element model, it was concluded that the bending stress in a few supporting rods is below the yielding stress of mild steel. Nevertheless, failures of the supporting rods were observed as presented in Figure 9.

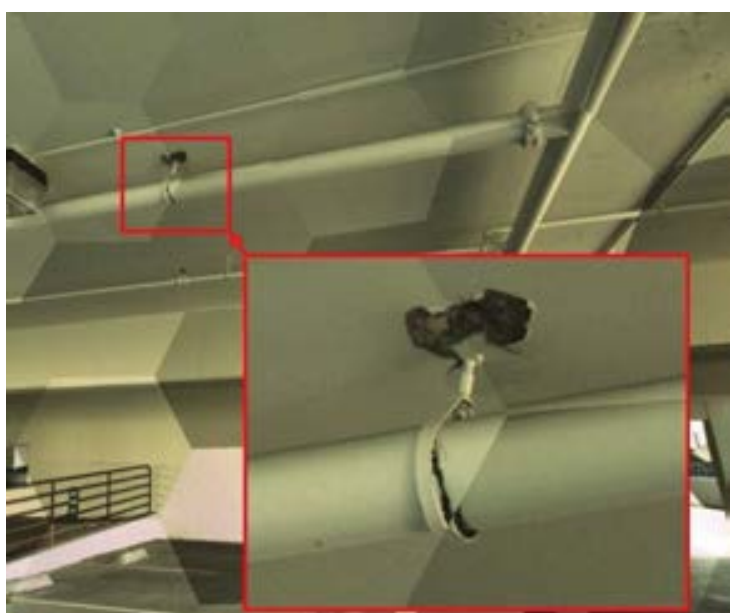

a) Large diameter pipe

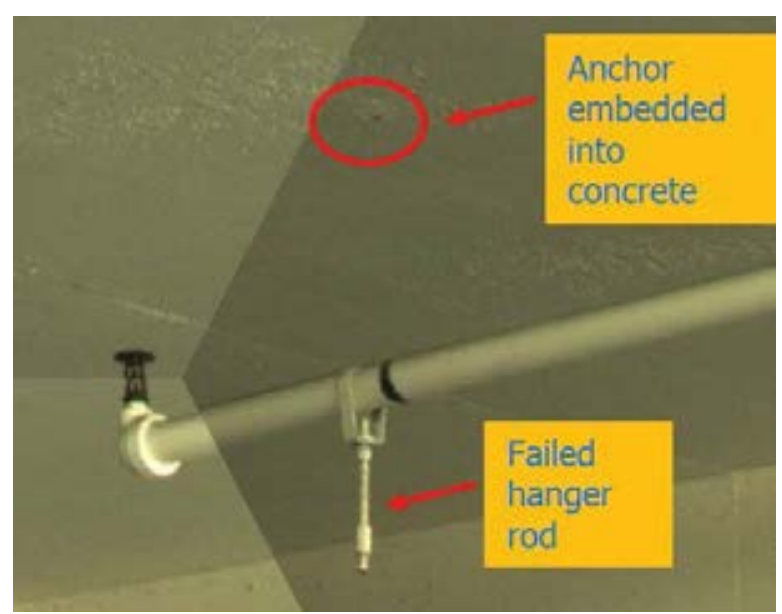

b) Small diameter pipe

Figure 9: Typical failures of supporting rods [1].

The failure in the right image is related to the low-cycle fatigue capacity of the smaller rods in bending. As opposed to that, the left image shows a failure of the larger supporting rod that resulted from the failure of the anchoring part of the rod. The anchor's depth was not sufficient to avoid a failure of the concrete. These nonlinear effects will be modelled in the next stage of the finite element modelling. This part of the finite element modelling is ongoing. In this stage a number of component tests will be performed to generate a realistic model. 


\section{ACKNOWLEDGMENTS}

The laser scans were collected during operations of nees@berkeley which was supported by the National Science Foundation (NSF). Special thanks are due to Smart Scanning Solutions, LLC (Tashkent, Uzbekistan) for the extensive work on converting the point cloud into solids. The authors would like to acknowledge Sensor Fusion and Monitoring Technologies, LLC (USA) for providing access to the portable data acquisition system. Special thanks are due to Holly Halligan of UC Berkeley for editing the paper.

\section{CONCLUSIONS}

- Based on the laser scans of a parking structure a finite element model of the fire-sprinkler piping system was generated.

- To estimate the dominant frequencies of the structure it was studied via ambient vibration tests.

- A few assumptions were made for the first stage of modelling. The resulting simplified model was studied in a linear time history analysis.

- The results of the first stage clearly show larger stresses as the locations of the observed failures, although they were below the yielding stress of mild steel.

- The first stage analysis shows a strong need for non-linear analysis based on component testing of typical connections. This part of the study is ongoing.

\section{REFERENCES}

[1] S. Takhirov, K.M. Mosalam, F. Cakir, S. Günay (2017). 'Performance of Fire Sprinkler Systems in the 2014 South Napa Earthquake: Numerical Modelling with Validation by Laser Scans of Aftermath'. The 16th World Conference on Earthquake Engineering. January 7-13, 2017 Santiago, Chile.

[2] Leica Geosystems AG (2011). Leica ScanStation C10. https://w3.leicageosystems.com/downloads123/hds/hds/ScanStation\%20C10/brochuresdatasheet/Leica_ScanStation_C10_DS_en.pdf.

[3] Leica Geosystems (2018). Cyclone Version 9.2.1.

[4] Pacific Instruments, Inc. Inc. (2017). http://catalog.pacificinstruments.com/Asset/6008U_Enclosure\%204slot $\% 2012$ V\%20DC\%20USB\%20Control\%20\&\%20Data\%20Interface.pdf last retrieved on $11 / 23 / 20$.

[5] International Code Council Evaluation Service Inc. (ICC-ES), 2015. 'Acceptance Criteria for Seismic Qualification by Shake-Table Testing of Nonstructural Components and Systems, AC156', ICC-ES.

[6] The United States Geological Survey (USGS). https://www.usgs.gov/naturalhazards/earthquake-hazards/hazards (last accessed on 04/16/2021). 
[7] Amir Gilani and Shakhzod Takhirov. 'Current U.S. practice of seismic qualification of suspended ceilings by means of shake table tests', INGEGNERIA SISMICA journal, Italy: Vol. XXVIII, No. 1, pp. 26-42, 2011.

[8] Computers and Structures, Inc., CSI (2014): SAP2000 Ultimate Version 16.1.1. Structural Analysis Program. 